\title{
Pathogenicity of some commercial formulations of entomopathogenic fungi on the tomato leaf miner, Tuta absoluta (Meyrick) (Lepidoptera: Gelechiidae)
}

\author{
Assinapol Ndereyimana ${ }^{1,2^{*}}$ D, Samuel Nyalala ${ }^{1}$, Patrick Murerwa ${ }^{1}$ and Svetlana Gaidashova ${ }^{2}$
}

\begin{abstract}
The tomato leaf miner, Tuta absoluta (Meyrick) (Lepidoptera: Gelechiidae), is a major threat to tomato production in Rwanda. Laboratory bioassays were conducted to evaluate some commercial entomopathogenic fungi (EPF) formulations on T. absoluta larvae. The larvae, inside the leaf galleries, were obtained from the established tomato field. Commercial EPF: Metatech ${ }^{\circledR}$ WP [Metarhizium anisopliae (Metschn.) Sorok, Strain FCM Ar 23B3], Beauvitech ${ }^{\oplus}$ WP [Beauveria bassiana (Bals.) Vuill., Strain J25], and Botanigard ES [B. bassiana (Bals.), Strain GHA] were tested in Petri dishes against T. absoluta larvae at a concentration of $10^{8}$ spores $/ \mathrm{ml}$. A synthetic insecticide, imidacloprid was included for comparison as a positive control, while water was used as a negative control. All the tested commercial EPF formulations were pathogenic to T. absoluta larvae in all conducted bioassays. Mortality rates increased with an increase in time (days). However, the insignificant difference was observed in the mortality of $T$. absoluta larvae treated with the commercial EPF during the first 3 days in all bioassays. Highly significant differences $(p<0.01)$ in pathogenicity among treatments were observed from the 4th to 6 th days after inoculation. Metatech ${ }^{\circledR}$ WP and Beauvitech ${ }^{\oplus}$ WP recorded the highest mortality rates (82.8 and 60.8\%) with the $L_{50}$ values of 3.9 and 5.2 days, respectively, while imidacloprid caused the least larval mortality. Since the EPF demonstrated high virulence level against the target pest, the efficacy of Metatech ${ }^{\circledR}$ WP and Beauvitech ${ }^{\circledR}$ WP should be advanced to field evaluation to determine their potential as alternatives to the synthetic insecticides.
\end{abstract}

Keywords: Tuta absoluta, Entomopathogenic fungi, Beauveria bassiana, Metarhizium anisopliae, Biological control, Rwanda

\section{Background}

Despite its economic and nutritional importance, tomato production in Rwanda is challenged by various factors, including the prevalence of pests and diseases, limited skills in pest and disease management, as well as lack of appropriate pest management options (Clay and Turatsinze 2014). The tomato leaf miner, Tuta absoluta (Meyrick) (Lepidoptera: Gelechiidae), is a major threat to tomato production in Rwanda since the year 2015 (FAO 2015). It damages the plant by

\footnotetext{
* Correspondence: assinapol@gmail.com

'Department of Crops, Horticulture and Soils, Egerton University, Nakuru, Kenya

${ }^{2}$ Agriculture Research and Technology Transfer Department, Rwanda

Agriculture and Animal Resources Development Board (RAB), Kigali, Rwanda
}

mining the leaves and boring into the stems and fruits, resulting in reduced tomato yield and fruit quality (Brévault et al. 2014). The mines and holes inflicted by this pest also serve as entry points for secondary infectious pathogens. Tomato production losses reached up to $100 \%$ due to this pest (Desneux et al. 2010).

So far, little has been done to develop an integrated pest management (IPM) program fitting to Rwandan conditions for this pest. T. absoluta control in Rwanda is mainly based on chemical insecticides; which affects the populations of beneficial organisms, especially pollinators and natural enemies and causes water pollution and disturbance of aquatic ecosystems as well as human health problems (Shalaby et al. 2013). Furthermore, the continuous use of chemical pesticides has been reported 
to result in the build-up of resistant biotype populations of T. absoluta (Yalçin et al. 2015).

Numerous studies have been conducted on entomopathogenic fungi (EPF) to control a diversity of pests that showed to be highly effective (Contreras et al. 2014). Specifically, Beauveria bassiana (Bals.) Vuill. (Ascomycota: Hypocreales) and Metarhizium anisopliae (Metsch.) Sorok (Ascomycota: Hypocreales) have been in use against insect pests for more than 120 years (Contreras et al. 2014). These fungi have important features which make them the potential agents for biological control; they are widely distributed in nature, easily isolated from insect cadavers or from soil, have the ability to be cultured in laboratory on simple media and conserved by storing conidia in glycerol solutions, and easily mass-produced and formulated as a bio-insecticides (Qazzaz et al. 2015).

Different scientists reported that $T$. absoluta control can be achieved in environmentally friendly way using B. bassiana (Qazzaz et al. 2015; El-Kichaoui et al. 2016) and M. anisopliae (Shalaby et al. 2013; Contreras et al. 2014). In laboratory experiments, these EPF were observed to infect and control T. absoluta larvae inside the leaf galleries and the adults emerged from treated pupae (Youssef 2015; El-Ghany et al. 2016). Since EPF mass production is cost-effective, they have substantial advantages of being used in biological control of $T$. absoluta.

Although biopesticides based on B. bassiana and $M$. anisopliae have been studied on T. absoluta, commercial formulations recommended against this pest are limited (Biondi et al. 2018). In Rwanda, there are no fungal strains registered for T. absoluta control. Besides, the global insecticide resistance action committee (IRAC 2011) recommended that the evaluation of the efficacy of different pesticides against $T$. absoluta in local conditions should be emphasized when designing an effective IPM program. This study was carried out to determine the pathogenicity of three selected commercial formulations of EPF, based on B. bassiana and $M$. anisopliae, against the Rwandan population of T. absoluta under laboratory conditions.

\section{Materials and methods}

\section{Site of study}

The study was conducted at the Biological Control Laboratory, Rwanda Agriculture and Animal Resource Development Board (RAB).

\section{Entomopathogenic fungi}

Three commercial biopesticides based on EPF were used in the study (Table 1). The EPF were cultured on Potato Dextrose Agar (PDA) media and incubated at $25 \pm 1{ }^{\circ} \mathrm{C}$ for 7 days to confirm their viability before being used (Youssef 2015). Observation under stereomicroscope at $\times 40$ magnification revealed that over $95 \%$ of spores had germinated in the all tested EPF. Dilutions were carried out for each EPF product to achieve a concentration of $10^{8}$ spores $/ \mathrm{ml}$.

\section{Tuta absoluta larvae}

Leaflets infested with $T$. absoluta larvae in the galleries were collected from a tomato crop cultivated in September, 2018 in a field located in Bugesera District, Rweru Sector. The tomato cultivar Roma was chosen because it is the most commonly grown by Rwandan farmers in open field conditions. The collected leaflets were transported in cloth bags to the laboratory and were kept for a maximum of $12 \mathrm{~h}$ before being used in the experiment.

\section{Laboratory bioassays}

Three successive bioassays were conducted on different dates during the period of November-December, 2018. Petri dishes $(9 \mathrm{~cm}$ diameters), lined with three moistened filter paper discs, were used as bioassay arenas. Each leaflet, with one third instar larva $(3.85-5.65 \mathrm{~mm})$ of $T$. absoluta in gallery, was placed in a Petri dish and treated on both sides with $2 \mathrm{ml}$ of a respective EPF at the dosage of $10^{8}$ spores $/ \mathrm{ml}$, using a sterile pipette. The excess of the applied volume was drained on a filter paper. A synthetic insecticide, imidacloprid $(1 \mathrm{ml} / \mathrm{l})$, and sterilized tap water were used as positive and negative controls, respectively. The Petri dishes $(n=10)$ were supplied by moisture (1 ml water) as needed to avoid desiccation of leaflets and ensure continuous and adequate moisture

Table 1 Commercial entomopathogenic fungi used in the experiment

\begin{tabular}{|c|c|c|c|}
\hline $\begin{array}{l}\text { Commercial } \\
\text { name }\end{array}$ & Active ingredient and concentration & Manufacturer & Distributor \\
\hline${\text { Metatech }{ }^{\circledast} \text { WP }}$ & $\begin{array}{l}\text { Metarhizium anisopliae (Metsch.) Sorok, } \\
\text { Strain FCM Ar 23B3, } 5 \times 10^{9} \mathrm{CFUs} / \mathrm{gr}\end{array}$ & $\begin{array}{l}\text { Dudutech Division, Flamingo Horticulture (K) Ltd., } \\
\text { Naivasha, Kenya }\end{array}$ & $\begin{array}{l}\text { Elgon Kenya } \\
\text { Ltd. }\end{array}$ \\
\hline $\begin{array}{l}\text { Beauvitech }{ }^{\oplus} \\
\text { WP }\end{array}$ & $\begin{array}{l}\text { Beauveria bassiana (Bals.) Vuill., Strain J25, } \\
1 \times 10^{10} \text { CFUs/g }\end{array}$ & $\begin{array}{l}\text { Dudutech Division, Flamingo Horticulture (K) Ltd., } \\
\text { Naivasha, Kenya }\end{array}$ & $\begin{array}{l}\text { Elgon Kenya } \\
\text { Ltd. }\end{array}$ \\
\hline Botanigard $^{\oplus} \mathrm{ES}$ & $\begin{array}{l}\text { Beauveria bassiana (Bals.) Strain GHA, } 2 \times 10^{13} \text { viable } \\
\text { spores/1.14 L }\end{array}$ & $\begin{array}{l}\text { LAM International Corp, USA } 117 \text { South Parkmont, } \\
\text { Butte, MT59701. }\end{array}$ & $\begin{array}{l}\text { Amiran Kenya } \\
\text { Ltd. }\end{array}$ \\
\hline
\end{tabular}

Source: Products' labels 
for spore germination (Shalaby et al. 2013), while a fresh leaflet was added every other day to prevent starvation of $T$. absoluta larvae. The Petri dishes were sealed by parafilm membrane to prevent dehydration and the escape of the larvae, and were maintained at $25 \pm 2{ }^{\circ} \mathrm{C}$ in dark. The whole bioassay process was carried out as a completely randomized design with four replications and was repeated three times.

\section{Data analysis}

Larval mortality was evaluated daily for 6 days postinoculation (Youssef 2015). The dead larvae were moved to Petri dishes lined with moistened filter paper to permit fungal growth on their bodies. After 5-10 days, the cause of death could be confirmed through fungal outgrowth on the dead larvae. The corrected mortality was calculated using Schneider-Orelli's formula (Püntener 1981):

$$
\text { Corrected mortality }=\frac{\text { Observed mortality }(\%)-\text { Control mortality }(\%)}{100-\text { Control mortality }(100)} \times 100 \text {. }
$$

Data of corrected mortality were checked for normality using SAS. To obtain a normally distributed data set, different transformations like log, square-root, and arcsine transformations were tried and the best one chosen by interpreting the output (Rangaswamy 2013). For the data of first bioassay, square-root transformation was used for day 4, while arcsine transformation was used for days 5 and 6 after inoculation. For the data of the second and third bioassays, log transformation was used for days 5 and 6 , while the data on day 4 were analysed without transformation. The effect of treatments on T. absoluta larval mortality was evaluated, using general linear model (GLM) procedure. Means for statistically different treatments were separated, using Tukey's honestly significant difference (HSD) test at 5\% level of significance. Lethal time to kill $50 \%$ of treated larvae $\left(\mathrm{LT}_{50}\right)$ was computed for all evaluated EPF formulations through probit analysis (Throne et al. 1995). Reciprocal square-root transformation of probit data was carried out before subjecting them to analysis of variance. All the analysis was performed using Statistical Analysis System package SAS software version 9.2 (SAS Institute 2010).

\section{Results and discussion}

The entomopathogenic fungi (EPF) used in this study, at a dosage of $10^{8}$ spores $/ \mathrm{ml}$, were pathogenic to $T$. absoluta larvae in all conducted bioassays. In all treatments, mortality rates increased with the increase in time (days). They were very low in the first 3 days and started to be significantly different among the treatments $(p<$ 0.01 ) from the fourth day after application (Fig. 1). Various studies also reported that $T$. absoluta control could be achieved by using M. anisopliae (Shalaby et al. 2013; Contreras et al. 2014; Shiberu and Getu 2017) and B. bassiana
(Qazzaz et al. 2015; Youssef 2015; El-Kichaoui et al. 2016). The results obtained form the basis for further studies on these EPF in a view to find the appropriate ways of using them under field conditions.

The formulation based on $M$. anisopliae (Metatech WP) was insignificantly different from $B$. bassiana (Beauvitech $^{\oplus}$ ) in all bioassays on days 5 and 6, except on day 5 of bioassay one. In most cases, Metatech ${ }^{\oplus}$ WP recorded higher mortality rates than Botanigard ${ }^{\circ} \mathrm{ES}$ (B. bassiana, Strain GHA) and imidacloprid in all bioassays. The highest mortality rates observed were $82.8,60.8,48.8$, and $33.5 \%$ for Metatech $^{\odot}$ WP, Beauvitech ${ }^{\oplus}$ WP, Botanigard ${ }^{\oplus}$ ES and imidacloprid (control), respectively (Fig. 1). Higher virulence of $M$. anisopliae compared to $B$. bassiana was also reported by Murerwa et al. (2014) against the aphids Rhopalosiphum padi and Metopolophium dirhodum.

Conflicting results were obtained by Moawad et al. (2017), who reported that B. bassiana was more effective than $M$. anisopliae in all treated larval instars of Stomphastis thraustica (Meyrick) (Lepidoptera: Gracillariidae), a leaf miner of Jatropha curcas. Similarly, Youssef (2015) observed a high-mortality rate of $T$. absoluta larvae inside the galleries with $B$. bassiana (86.7\%) than with $M$. anisopliae (76.7\%), using a dosage of $10^{8}$ spores $/ \mathrm{ml}$. This could be explained by the fact that the pathogenicity of a particular entomopathogen depends on strain/isolate and environment, among others (Borisade and Magan 2014). Thus, screening different EPF species and strains against a particular target host is crucial in development of any control program (Georgis et al. 2006).

At the dosage of $10^{8}$ spores $/ \mathrm{ml}$, the highest mortality rates recorded in the present study were 82.8 and $60.8 \%$ for $M$. anisopliae and B. bassiana, respectively. Nevertheless, other studies could obtain higher mortality levels of $T$. absoluta larvae inside the leaf mines with higher dosages. For instance, Youssef (2015) observed a mortality rate of $90 \%$ in $T$. absoluta larvae inside the galleries with $B$. bassiana at a dosage of $10^{10}$ spores $/ \mathrm{ml}$; while ElKichaoui et al. (2016) obtained up to $95 \%$ mortality of $T$. absoluta larvae, using B. bassiana at a dosage of $2.5 \times$ $10^{7}$ spores $/ \mathrm{ml}$. This concurs with the findings of Shalaby et al. (2013) who reported a linear relationship between mortality rate of $T$. absoluta and concentrations of $B$. bassiana and M. anisopliae.

In all bioassays, the mortality observed in tomato leaflets treated with imidacloprid, the synthetic insecticide mostly used by farmers, was the least than EPF application (Fig. 1). The limited efficiency of imidacloprid could be due to the ability of $T$. absoluta to develop resistant strains to the frequently used synthetic insecticides (Yalçin et al. 2015; Biondi et al. 2018). Likewise, the resistance of $T$. absoluta to indoxacarb and chlorantraniliprole was detected by Roditakis et al. 
(A)

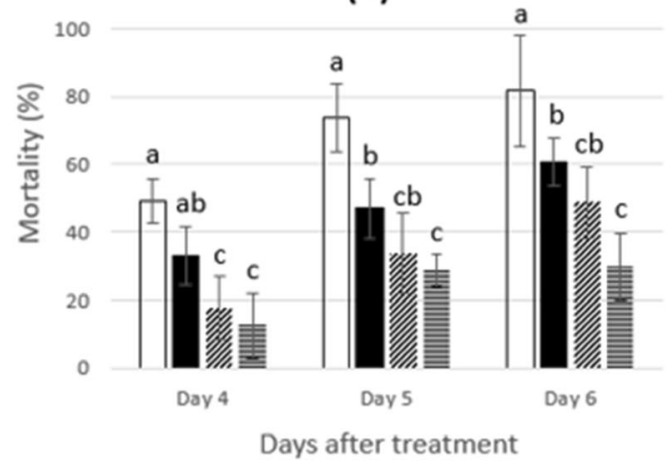

$\square$ Metatech ${ }^{\bullet}$ WP

(M. anisopliae, Strain FCM Ar 23B3)

- Beauvitech ${ }^{\ominus}$ WP

(B. bassiana, Strain J25)

\% Botanigard ES

(B. bassiana, Strain GHA)

玉 Imidaclopride

(B)

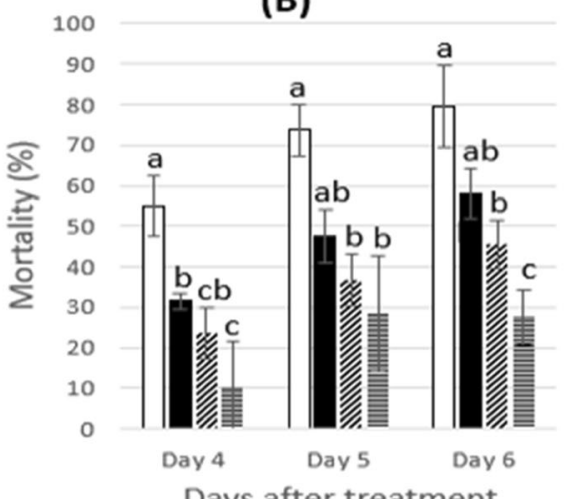

(C)

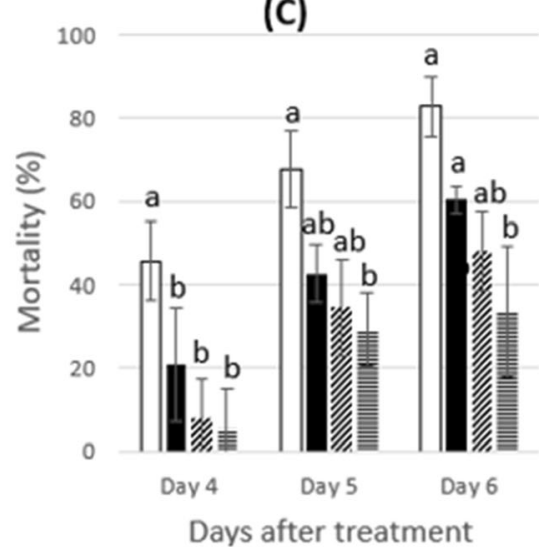

Fig. 1 Mortality (\%) of Tuta absoluta larvae treated with commercial EPF formulations ( $10^{8}$ spores $\mathrm{ml}^{-1}$ ) and imidacloprid (control) in bioassays one (a), two (b), and three (c). Different letters above bars (mean + SD) within the same day indicate significant difference according to Tukey test $(p<0.05)$

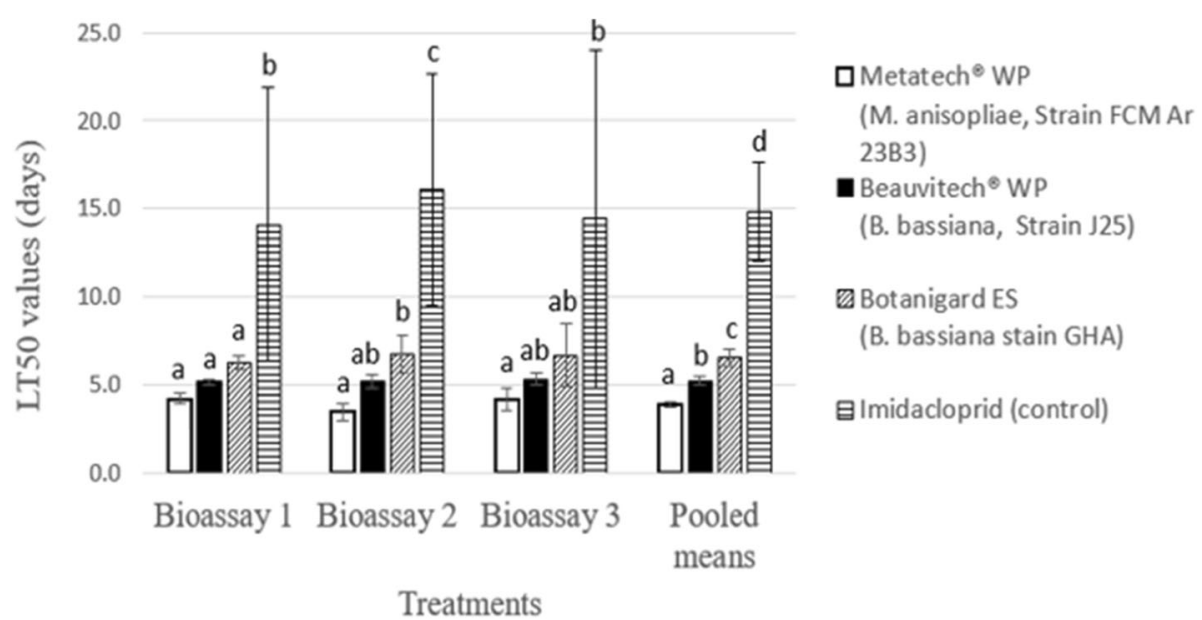

Fig. 2 Lethal time in days to control 50\% of Tuta absoluta larvae treated with commercial EPF formulations $\left(10^{8}\right.$ spores $\left.\mathrm{ml}^{-1}\right)$ and imidacloprid $\left(1 \mathrm{ml} \mathrm{L}^{-1}\right)$. Different letters above the means + SD bars indicate significant difference within the same bioassay according to Tukey test $(p<0.05)$ 
(2013) in three laboratories belonging to the three different countries, Greece, Italy, and Spain. In Turkey, the resistance of $T$. absoluta to five commonly used insecticides, spinosad, indoxacarb, metaflumizone, and chlorantraniliprole, was also recorded by Yalçin et al. (2015).

In the all three bioassays, the lowest $\mathrm{LT}_{50}$ values were recorded by Metatech ${ }^{\circ} \mathrm{WP}$, followed by Beauvitech ${ }^{\circ} \mathrm{WP}$, Botanigard $^{\circ}$ ES and imidacloprid, respectively (Fig. 2). The general linear model (GLM) analysis of the pooled means for three bioassays indicated that $\mathrm{LT}_{50}$ values were 3.9, 5.2, 6.6, and 14.9 days for Metatech WP, Beauvitech ${ }^{\circ}$ WP, Botanigard $^{\circ}$ ES, and imidacloprid, respectively. Metatech $^{\circ}$ WP gave the lowest $\mathrm{LT}_{50}$ values; therefore, it is more pathogenic than the other evaluated EPF.

\section{Conclusion}

Metatech WP (M. anisopliae, Strain FCM Ar 23B3) exhibited the highest pathogenicity to T. absoluta, followed by Beauvitech ${ }^{\circ}$ WP (B. bassiana, Strain J25). The pathogenicity was judged by considering the $\mathrm{LT}_{50}$ and the time required. Further field evaluations should be carried out to determine the potential of EPF as alternatives to chemical insecticides.

\section{Acknowledgements}

The authors are grateful to Rwanda Agriculture and Animal Resources Development Board and Egerton University for providing all facilitations to this work. Dr. Rukundo Placide, Mr. Kagiraneza Boniface, Ms. Bancy Waweru, Ms. Kajuga Joelle, Ms. Mukundwa Primitive, and Mr. Bazagwira Didace are also recognized for their technical support and assistance in laboratory work.

\section{Authors' contributions}

All authors designed the study. AN conducted the laboratory bioassays, performed data analysis, and drafted the manuscript. SN, PM, and SG helped in data analysis and added their inputs in the drafted manuscript. All authors read and approved the final manuscript.

\section{Funding}

This material is based upon work supported by United States Agency for International Development, as part of the Feed the Future initiative, under the CGIAR Fund, award number BFS-G-11-00002, and the predecessor fund the Food Security and Crisis Mitigation II grant, award number EEM-G-00-04-00013.

\section{Availability of data and materials}

The datasets used and/or analysed during the current study are available from the corresponding author on reasonable request.

\section{Ethics approval and consent to participate}

Not applicable.

\section{Consent for publication}

Not applicable.

\section{Competing interests}

The authors declare that they have no competing interests.

Received: 27 August 2019 Accepted: 21 October 2019

Published online: 18 November 2019

\section{References}

Biondi A, Guedes RNC, Wan FH, Desneux N (2018) Ecology, worldwide spread, and management of the invasive South American tomato pinworm, Tuta absoluta: past, present, and future. Annu Rev Entomol 63:239-258
Borisade OA, Magan N (2014) Growth and sporulation of entomopathogenic Beauveria bassiana, Metarhizium anisopliae, Isaria farinosa and Isaria fumosorosea strains in relation to water activity and temperature interactions. Biocontrol Sci Techn 24(9):999-1011

Brévault T, Sylla S, Diatte M, Bernadas G, Diarra K (2014) Tuta absoluta Meyrick (Lepidoptera: Gelechiidae): a new threat to tomato production in subSaharan Africa. Afr Entomol 22(2):441-444

Clay D, Turatsinze J (2014) Baseline report on the Rwanda horticulture Organisations survey. AGRER Consortium, Kigali, Rwanda p 92

Contreras J, Mendoza JE, Martínez-Aguirre MR, García-Vidal L, Izquierdo J, Bielza P (2014) Efficacy of Enthomopathogenic fungus, Metarhizium anisopliae, against Tuta absoluta (Lepidoptera: Gelechiidae). J Econ Entomol 107(1):121-124

Desneux N, Wajnberg E, Wyckhuys KAG, Burgio G, Arpaia S, Narváez-Vasquez CA et al (2010) Biological invasion of European tomato crops by Tuta absoluta: ecology, geographic expansion and prospects for biological control. J Pest Sci 83(3):197-215

El-Ghany NMA, Abdel-Razek AS, Ebadah IMA, Mahmoud YA (2016) Evaluation of some microbial agents, natural and chemical compounds for controlling tomato leaf miner, Tuta absoluta (Meyrick ) (Lepidoptera : Gelechiidae). J Plant Prot Res 56(4):373-379

El-Kichaoui A, El-Shafai A, Muheisen H, Mosleh F, El-Hindi M (2016) Safe approach to the biological control of the tomato leaf miner, Tuta absoluta, by entomopathogenic fungi Beauveria bassiana isolates from Gaza strip. Int J Appl Res 2(4):351-355

FAO (2015) Quarterly early warning bulletin for food and agriculture, p 18 Georgis R, Koppenhöfer AM, Lacey LA, Bélair G, Duncan LW, Grewal PS, Samish M, Tan L, Torr RV, Tol RWHM (2006) Successes and failures in the use of parasitic nematodes for pest control. BioControl 38(1):103-123

Insecticide Resistance Action Committee (IRAC) (2011) Tuta absoluta. The Tomato Leaf miner or Tomato Borer, Irac, p 16

Moawad SS, Mahmoud YA, Ebadah IMA, Sadek HE, Lotfy DE (2017) Controlling of Stomphastis thraustica (Meyrick) (Lepidoptera: Gracillariidae) by using Entomopathogenic Fungi. Int J Curr Microbiol Appl Sci 6(12):3976-3982

Murerwa P, Arama PF, Kamau AW, Maniania NK (2014) Pathogenicity of fungal isolates of Metarhizium anisopliae (Metchnikoff) and Beauveria bassiana (Balsamo) against aphids Rhopalosiphum padi (Linnaeus) and Metopolophium dirhodum (Walker). Egerton J Sci Technol 14:105-119

Püntener W (1981) Manual for field trials in plant protection, Second edn. Agricultural Division, Ciba-Geigy Limited. Basel, Switzerland

Qazzaz FO, Al-Masri MI, Barakat RM (2015) Effectiveness of Beauveria bassiana native isolates in the biological control of the Mediterranean fruit Fly (Ceratitis capitata). Adv Entomol 3(2):44-55

Rangaswamy R (2013) Textbook of agricultural statistics. new age international, New Delhi, p 531

Roditakis E, Skarmoutsou C, Staurakaki M, Martınez-Aguirre MR, Garcıa-Vidal L, Bielza P, Haddi K, Rapisarda C, Rison JL, Bassi A, Teixeira LA (2013) Determination of baseline susceptibility of European populations of Tuta absoluta (Meyrick) to indoxacarb and chlorantraniliprole using a novel dip bioassay method. Pest Manag Sci 69(2):217-227

SAS Institute Inc (2010) SAS ${ }^{\oplus} 9.2$ companion for windows, second edition. SAS Institute Inc, Cary, NC

Shalaby HH, Faragalla FH, El-Saadany HM, Ibrahim AA (2013) Efficacy of three entomopathogenic agents for control the tomato borer, Tuta absoluta (Meyrick) (Lepidoptera: Gelechiidae). Nat Sci 11(7):63-72

Shiberu T, Getu E (2017) Entomopathogenic effect of Beauveria bassiana (Bals.) and Metarrhizium anisopliae (Metschn.) on Tuta absoluta (Meyrick) (Lepidoptera: Gelechiidae) larvae under laboratory and glasshouse conditions in Ethiopia. J Plant Pathol Microbiol 8:411-414

Throne JE, Weaver DK, Chew V, Baker JE (1995) Probit analysis of correlated data: multiple observations over time at one concentration. J Econ Entomol 88(5): 1510-1512

Yalçin M, Mermer S, Kozaci LD, Turgut C (2015) Insecticide resistance in two populations of Tuta absoluta (Meyrick, 1917) (Lepidoptera: Gelechiidae) from Turkey. Türk Entomol Derg 39(2):137-145

Youssef AN (2015) Efficacy of the entomopathogenic nematodes and fungi for controlling the tomato leaf miner, Tuta absoluta (Meyrick) (Lepidoptera : Gelechiidae). Arab Univ J Agri Sci 23(2):591-598

\section{Publisher's Note}

Springer Nature remains neutral with regard to jurisdictional claims in published maps and institutional affiliations. 